\title{
Eye-movement patterns in selective listening tasks of focused attention*
}

\author{
DANIEL GOPHER \\ Tel-Aviv University, Ramat-A viv, Tel-Aviv, Israel
}

\begin{abstract}
Three experiments are described in which eye movements (Ems) were recorded in conjunction with either monaural or dichotic tasks of focused attention. Two main effects were observed in the Ems records: (1) Listening to auditory messages reduced the occurrence of spontaneous Ems. (2) Selective monitoring of one ear in the dichotic task was accompanied by a consistent pattern of directional Ems characterized by big saccades and long changes of eye fixation in the direction of the relevant ear. The pattern of Ems is affected by the following variables: the presentation rate of the auditory information, the frequency of demands to switch orientation between the ears, and the competition of the irrelevant channel in the dichotic task. It is suggested that the eye-movement mechanism is used in selective listening tasks as a general orientation indicator, when the adoption or maintenance of a certain selective set is difficult and demanding of effort. The Ems response is part of a general orientation pattern, although its usual function is in the field of visual perception.
\end{abstract}

The present study of eye movements (Ems) in selective listening tasks was suggested by incidental observation of the behavior of Ss in a dichotic listening test of focused attention (Gopher \& Kahneman, 1971). Selective monitoring of one ear was frequently accompanied by a large eye movement in the direction of that ear. Among the Ss who were aware of these movements, there was one who stated, "... If I look to the right, I can listen to the right ear. If I look to the left, I can listen to the left ear..." This correspondence between Ems and selective listening, so naturai for the naive $S$, seems to pose a difficult question for the experimental psychologist, since the dichotic messages were presented directly through headphones and no kind of visual processing was required.

Eye-movement responses have not been reported in the literature dealing with dichotic listening, although this paradigm has been employed in a large number of selective attention studies during the last two decades (for a detailed review, see Broadbent, 1958; Kahneman, 1973). The systematic investigation of this new aspect of $\mathrm{Ss}^{\prime}$ behavior may therefore contribute to our understanding of the nature and character of the selective listening process.

In addition, the recording of eye movements in selective listening tasks offers a new experimental situation for the investigation of the Ems mechanism. Here, again, it can be noted that, although there exists a large body of research describing Ems patterns in visual processing, learning situations, concept formation tasks, dreaming, imagining, and hypnosis, there is no research dealing with situations similar to the selective listening

\footnotetext{
*This research is based on a dissertation submitted to the Faculty of Social Sciences at the Hebrew University of Jerusalem, in partial fulfillment of the requirements for a doctoral degree. Thanks are due to Professor Daniel Kahneman for his help and guidance in all phases of this work. and to the Institute of Aviation Medicine of the Isracli Air Force, where these experiments were conducted.
}

task, where the $S$ is fully occupied with processing of external stimulation which is definitely not visual. (For a general review of the psychological literature dealing with Ems, see, for example: Yarbus, 1967; Mackworth \& Bruner, 1966; Kahneman, 1973.)

\section{GENERAL METHOD}

\section{Apparatus}

Ss were seated in a rotating chair (E.F. Tonnies), equipped with restraining belts and a convenient headrest. Two positions of the rotating chair were used. During calibration of Ems, the $S$ faced a metal cross with a central lamp and four adjustable lamps, one on each of the arms. During the presentation of auditory messages, the $S$ was half surrounded by a white curtain shaped as a cylinder, at a distance of $100 \mathrm{~cm}$. Auditory messages were always presented through stereophonic headphones (A.K.G. 50/400 ohm) connected to a stereophonic tape recorder (Ferrograph-724).

Ems were measured by the Electro-Oculograph (E.O.G.) method (Schackel, 1967), using an I.S.E. eight-channel recorder. Eight-millimeter silver electrodes were used, fastened to both temples. Only horizontal Ems were recorded. Recording was in ac mode, with a relatively prolonged time constant of $4 \mathrm{sec}$, which permitted measurements of eye position. Paper speed was $6.5 \mathrm{~mm} / \mathrm{sec}$.

\section{Procedure}

All the experiments were conducted in the same general procedure, which consisted of two successive phases. First, there was a short phase of Ems calibration, in which the $S$ was instructed to follow a sequence of lights presented on the horizontal arms of the metal cross, spanning a total of $40 \mathrm{deg}$. symmetrically around the center. Then the chair was turned $90 \mathrm{deg}$ towards the cylindrical curtain, the $S$ was asked to put on the earphones, and the auditory task was introduced.

The two phases of calibration and of selective listening were described as independent tasks, and the fact the eye movements were monitored during the second phase was not emphasized.

\section{Subjects}

Ss were male candidates for flight training. flight cadets. or pilots undergoing routine medical examinations. The Ss' average 


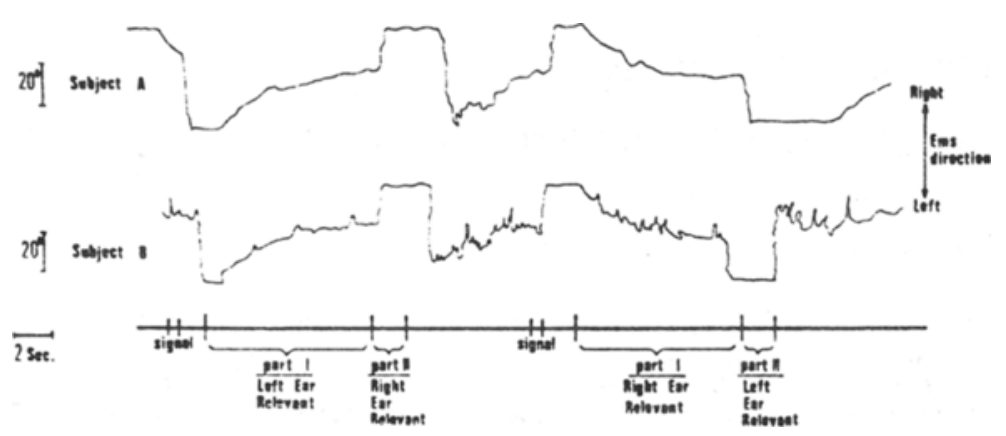

Fig. 1. An example of Ems records in a dichotic listening task.

age was 22. All were of good health and above average in intelligence.

\section{EXPERIMENT I}

Experiment I was planned to confirm the informal observations that systematic Ems occur during a task of selective auditory attention with dichotic messages.

\section{Method}

\section{Auditory Task}

The auditory task has been described in detail elsewhere (Gopher \& Kahneman, 1971). It comprises 48 test messages, each including the following sequence of events: (1) A spoken announcement of the message number, which $S$ is required to repeat. (2) After an interval of $2.5 \mathrm{sec}$, a $200-\mathrm{msec}$ indicator tone for Part $\mathrm{I}$ is presented, $2,500 \mathrm{~Hz}$ indicating that the right ear is relevant, $250 \mathrm{~Hz}$ indicating that the left ear is relevant. The indicator tone is always presented monaurally on the relevant ear. (3) A series of 16 pairs of items is presented to the two ears at a $2 / \mathrm{sec}$ rate, starting $1.5 \mathrm{sec}$ after the onset of the indicator tone. The items are either bisyllabic Hebrew verbs of the same vowel structure (e.g., naga or yada), with a stress on the second syllable, or digits from the set $0-9$. There are either two or four digits on the relevant channel and always six digits on the irrelevant channel. Digits on the two channels are never simultaneous. S's task is to repeat each relevant digit as soon as he hears it. (4) An indicator tone designating the relevant ear for Part II, as in Step 2 above; this tone is presented to the ear that was relevant in Part I. (5) After either one or two additional verbs, a final series of three pairs of digits is presented to the two ears. The $S$ is required to repeat the triad of digits heard by the relevant ear.

\section{Subjects}

Twenty-nine Ss participated in this experiment.

\section{Results}

Inspection of the Ems records during listening and responding to the auditory messages revealed a consistent pattern. The first indicator tone, which preceded the beginning of each dichotic presentation, usually elicited a large eye movement in the direction of the relevant ear. The beginning of the message itself was accompanied by an even larger movement in the same direction. The eyes usually pointed in the relevant direction during the entire $8 \mathrm{sec}$ of Part I. Occasional movements towards the center during this period were immediately followed by a return to the relevant direction. The second indicator tone which preceded the triads of numbers of Part II usually elicited the largest Ems in the relevant direction. Additional movements towards the relevant direction occurred at this time, even if the $S$ was not required to switch orientation from one ear to the other.

This general pattern of movements can be seen in Fig. 1, which shows an example of the Ems records of two Ss in two dichotic messages.

The figure shows that the eyes move and remain in the relevant direction (left for the first message and right for the second) during Part I of each test message. Sharp changes of fixation occur while the relevant ear is changed in Part II (the gradual drop of the line towards the center in Part I of each message is the result of the 4-sec time constant used and indicates that there was no change of eye's position during this period). We may note the great similarity between the Ss in the general pattern of movement. Major eye movements or changes of fixation occur at three points during the auditory messages: initial indicator, beginning of the message, and second indicator. Table 1 describes the percentages, averages, and standard deviations of Ems at these three points (deflections of $2 \mathrm{deg}$ and more were counted).

Table 1 indicates that Ems were frequent and large at the three points of measurement. Movements in the wrong directions were not found, but changes in the selective set were not always accompanied by relevant Ems. (The percentage of Ems does not reach $100 \%$ for any of the points).

Ems at the three points differ significantly in frequency and size. An analysis of variance of the size of Ems yielded a significant effect of condition $(F=12.46$, $\mathrm{df}=2 / 56, \mathrm{p}<.01)$, as well as a significant effect of individual differences $(F=10.36, \mathrm{df}=28 / 56, \mathrm{p}<.01$ ). These differences are consistent across conditions, and the Pearson coefficients of correlation between the

Table 1

Distribution of Ems at Three Points of Measirement

\begin{tabular}{lccc}
\hline & $\begin{array}{c}\text { Initial } \\
\text { Indicator }\end{array}$ & $\begin{array}{c}\text { Beginning } \\
\text { of a } \\
\text { Message }\end{array}$ & $\begin{array}{c}\text { Second } \\
\text { Indicator }\end{array}$ \\
\hline Relative Frequency & $73 \%$ & $83 \%$ & $90 \%$ \\
Average (in Degrees) & 14.5 & 17.1 & 19 \\
SD & 7.74 & 7.73 & 6.26 \\
\hline
\end{tabular}


individual Ems measures at the three points of measurement are in the range of $.84-.90$.

In addition to the inter-S variability, the analysis of each individual Ems record revealed marked inter-S variance over the 48 auditory messages. The main question in considering this variability is whether it reflects an ordered decrease in the Ems response as a result of a habituation process. To answer this question, average values of Ems were computed in successive quarters (12 messages) of the auditory task, for each of the three points of measurement. The analysis of variance of these values showed no significant decrement in the Ems response over time (the $F$ values were 1.22, $1.23,1.15, \mathrm{df}=3 / 27$ for first indicator, beginning of a message, and second indicator, respectively).

An additional analysis was concerned with the possible correspondence between parameters of eye movements and details of the Ss' performance in the attention test. Three main types of errors in selective listening were identified: omissions of relevant digits in Part $I$, intrusions of irrelevant digits in Part $I$, and errors in repeating triads of digits in Part II, after the second indicator tone. For a more detailed description, see Gopher and Kahneman (1971).

As in the previous study, pilots and flight cadets usually made few errors. In the present data, there were only 3\% omission errors (out of the total number of relevant digits to be reported), $0.8 \%$ intrusion errors (out of the total number of digits in the irrelevant channel), and $5.7 \%$ errors in reporting the Part II triads.

All the attempts to correlate features of the Ems records with failures of listening proved to be unsucessful. First, there was no difference in the percentage of errors between the messages which were accompanied by directional Ems and those which were not. Secondly, no measurable peculiarities of Ems were found to be associated with intrusion errors, where the S erroneously reported digits presented to the irrelevant ear. Finally, there was no significant correlation between Ss' total error scores and the overall frequency or size of Ems.

\section{Discussion}

The results indicate a regular and consistent pattern of eye movement in the dichotic listening task. This pattern is characterized by large saccades and relatively prolonged fixations in the direction of the relevant ear (i.e., the relevant channel of information). This pattern of reaction suggests the idea that the Ems accompany directional changes of selective attention. Nevertheless, the results indicate that such correspondence between Ems and the attention process is neither perfect nor essential to performance, since changes of selective set were not invariably accompanied by Ems. In addition, there was no correlation between Ems and specific errors of listening. Ems seem to be a frequent optional response rather than a reflexive behavior or a necessary accompaniment of changes in selective attention. This response usually co-occurs with the general changes in selective listening but is not sensitive to specific failures of this process.

The frequency and the size of Ems were significantly different at the three points of measurement (first indicator, beginning of a message, second indicator). Table 1 shows that the lowest values of the Ems measures are those of the first indicator, while the highest values are those of the second indicator. The results for the beginning of the message were intermediate.

The amount of effort demanded at the three points seems to differ. The first indicating tone was only a warning signal for the relevant channel. The beginning of the message demanded active processing and responding to the relevant items. Finally, the second indicator required a rapid reconsideration of the existing selective set and a change of orientation, if needed. This reconsideration was immediatley followed by simultaneous dichotic presentation of digits.

The second indicator seems, therefore, to be the major locus of difficulty and of demand for effort. This observation is confirmed by the verbal reports of the Ss and by the significantly higher percentage of errors at this point. (The difference also appeared in Gopher \& Kahneman, 1971, and was supported by a special control experiment). It seems reasonable, therefore, to suggest that the differences in the frequency and degree of Ems at these three points reflect differences in effort.

A more complete understanding of the nature and causes of Ems in selective listening tasks requires a better specification of the causes of the response. Is the locating of relevant information in a certain ear a sufficient condition for eliciting Ems in that direction? What is the effect of the frequent need to switch orientation from one ear to the other? Is there any effect of the presence of competing irrelevant information in the other ear? Experiments II and III were designed to examine these questions.

\section{EXPERIMENT II}

In this experiment, the auditory messages were presented monaurally. This technique was used to eliminate the possible effect of the competing irrelevant channel and the frequent demand to switch orientation from one channel to the other.

\section{Method}

\section{Auditory Task}

The auditory task was constructed from the same record used in Experiment I, with two changes: First, the Ss had to listen to only one channel; the other ear was silent. The relevant ear was switched after 24 messages, and the order of presentation was balanced over Ss. The S's task was to monitor and immediately report all digits. 


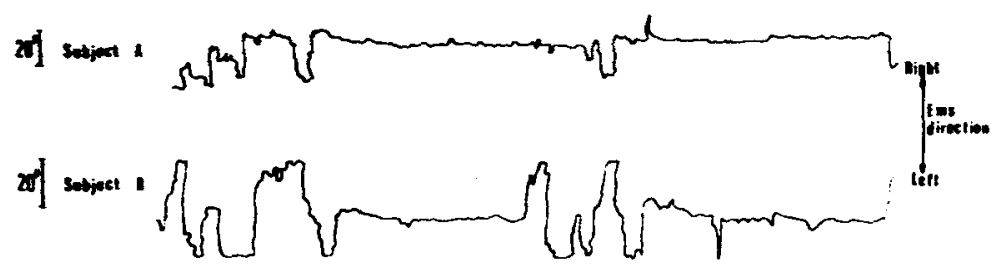

Fig. 2. An example of Ems records in a monaural listening task.

$\overline{2 s+c}$

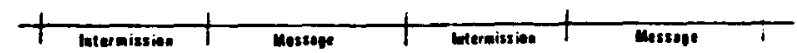

\section{Subjects}

Ten Ss participated in this experiment.

\section{Results}

The Ems records of the 10 Ss during the monaural listening task showed a consistent pattern of response, which differed markedly from the pattern observed in the dichotic task of Experiment I. During the messages, fixation was generally central and there was a marked inhibition of Ems. In contrast to this inhibition during the listening periods, pauses between messages were characterized by the frequent occurrence of large saccades. This general pattern is illustrated in Fig. 2, which presents an example of Ems records of two Ss in two messages of the monaural task.

The size of the movements during the message is negligible, when compared with the large Ems that occur during intermissions. The average number of Ems spanning $2 \mathrm{deg}$ or more per $10 \mathrm{sec}$ of message was .70 , whereas the comparable value for pauses was 4.97 . This difference is highly significant $(t=5.55, \mathrm{df}=9, \mathrm{p}<.01)$. Table 2 describes the two periods with regard to the size of Ems.

Table 2 shows that most of the Ems during the listening period were relatively small, while the movements during pauses were usually much larger.

\section{Discussion}

The elimination of the dichotic competition and of the frequent need to switch orientation between the ears caused a significant change in the general pattern of the Ems response. The big saccades and the prolonged fixations in the direction of the relevant ear disappeared. The mere presentation of the relevant auditory information to one ear does not elicit eye movements and changes of fixation in that direction. It seems, therefore, that Ems in selective listening tasks cannot be explained in terms of a simple response of orientation towards the source of the relevant information.

This demonstration, that spatial location is not sufficient for the elicitation of Ems, suggests again the idea that the "difficulty," "load," or "demanded effort" of the listening task may have a determining role in the production of the pattern of Ems observed in
Experiment I. This idea will be further examined in Experiment III.

The general inhibition of ocular motility during listening periods can be linked with several other studies which have reported a similar inhibition of Ems in different experimental situations. Gaarder (1966) recorded the fine eye movements of Ss instructed to focus attention on visual targets. He reported that periods of inattention can be differentiated from periods of focused attention by the many small Ems during inattention as against Ems inhibition during focused attention periods. However, it must be noted that Ems in Gaarder's task were much smaller.

Several studies have been reported in which Ems were recorded together with other physiological measures, such as heart rate and chin EMG, in classical conditioning situations and reaction-time tasks (Obrist, Webb, \& Perez-Reyes, 1965; Obrist, Webb, \& Sutterer, 1969, 1970; Webb \& Obrist, 1970). These studies have described a pattern of inhibition that is observed when Ss concentrate or prepare themselves for incoming information. The inhibition was most clearly manifested in the Ems records, which these investigators considered to be the best indicator. The inhibition of Ems was viewed as part of a more general inhibitory mechanism which stops or reduces irrelevant ongoing physiological activities while the organism concentrates and focuses attention. The inhibition of Ems in the selective listening task of the present experiment is consistent with the suggestion of a general inhibitory tendency in situations of information intake.

\section{EXPERIMENT III}

Experiment III was designed to study the effect of presentation rate and of frequent demands to switch attention from one ear to the other on the Ems

Table 2

Distribution of Ems During Listening Periods and Pauses

\begin{tabular}{ccc}
$\begin{array}{c}\text { Size of } \\
\text { Movement } \\
\text { (in Degrees) }\end{array}$ & $\begin{array}{c}\text { Messages } \\
\text { (Percent) }\end{array}$ & $\begin{array}{c}\text { Pauses } \\
\text { (Percent) }\end{array}$ \\
\hline $2-9$ & 55.7 & 29.5 \\
$10-19$ & 33.9 & 37.9 \\
$20+$ & 10.4 & 32.5 \\
Total & 100.0 & 99.9 \\
\hline
\end{tabular}


response. Monaural presentation was used again, but the information was frequently switched between the ears.

\section{Method}

\section{Auditory Task}

The $\mathrm{S}$ was exposed to three lists of randomly ordered digits, each lasting $90 \mathrm{sec}$. The three lists differed in presentation rate: rates of $1 / 0.5 \mathrm{sec}, 1 / 0.75 \mathrm{sec}$, and $1 / \mathrm{sec}$ were used. Information was monaurally presented and alternated from one ear to the other after periods of 2,4 , or $6 \mathrm{sec} .1$ In each list, the three periods were equally fsequent and appeared in random order. The S's task was to immediately report all digits.

\section{Subjects}

Twelve Ss took part in this experiment. The order of presentation of the lists was counterbalanced so that each of the six possible permutations was presented to two of the Ss.

\section{Results}

Eye movements occurred when information was switched from one ear to the other. However, the frequency and size of these Ems were much smaller than those observed in the dichotic task of Experiment $I$.

Table 3 presents the relative frequency and average size of Ems at the three rates of presentation (deflections of $2 \mathrm{deg}$ and more were counted).

The average values presented in Table 3 are relatively low in comparison with Table 1, Experiment 1 . The frequency and size of Ems increased as the rate of presentation increased, but even at the fastest rate $(1 / 0.5 \mathrm{sec})$, their frequency reached only $50 \%$, and their average size was $5.36 \mathrm{deg}$.

Significant differences were observed between the rates of presentation $(F=4.10, \mathrm{df}=2 / 22, \mathrm{p}<.05)$ and between Ss $(F=2.55, \mathrm{df}=11 / 22, \mathrm{p}<.05)$.

The Ems measures obtained at the presentation rate of $1 / 0.5 \mathrm{sec}$ can be compared with those obtained in Experiment I, which used the same presentation rate. The most adequate point of comparison of the three measures in Experiment I seems to be the beginning of the message, where the $\mathrm{S}$ was instructed to listen to one ear. The frequency of Ems at this point in the dichotic task of Experiment I was $83 \%$ against $50 \%$ in the present experiment. The difference is even more pronounced if the average degree of movement is considered: $17.1 \mathrm{deg}$ as against $5.36 \mathrm{deg}(t=6.65$, $p<.001$ ). Since the rate of presentation in both experiments was the same and the demand to switch orientations was actually more frequent in the present experiment, the main cause for the differences in Ems seems to be the presence of interfering irrelevant information in Experiment $\mathbf{I}$.

\section{GENERAL DISCUSSION}

The combined results of the three experiments indicate two main effects of the selective listening task
Table 3

Distribution of Ems at the Three Rates of Presentation

\begin{tabular}{lccc} 
& $1 / 0.5 \mathrm{Sec}$ & $1 / 0.75 \mathrm{Sec}$ & $1 / 1 \mathrm{Sec}$ \\
\hline Relative Frequency & $50.04 \%$ & $46.10 \%$ & $34.10 \%$ \\
Average (in Degrees) & 5.36 & 4.20 & 2.8 \\
SD & 3.55 & 2.87 & 1.91 \\
\hline
\end{tabular}

on the Ems response. First, listening and responding to auditory messages seems to inhibit the spontaneous occurrence of Ems (Experiment II). In addition, the demand to adopt and maintain a selective auditory set is frequently accompanied by voluntary directional Ems (Experiments I and III). The inhibition of spontaneous Ems is clearly manifested in the results of Experiment II, but should also have been found in the other two experiments. However, the detection of such inhibition in the results of Experiments I and III is difficult to achieve since it is confounded by the voluntary directional Ems. The inhibition of spontaneous Ems is linked with the operation of a general inhibiting mechanism suggested by Obrist et al $(1965,1969,1970)$ and Webb and Obrist (1970), which reduces irrelevant physiological activities in periods of concentration.

Three main variables were found to have an effect on the frequency and average size of the directional Ems in the selective listening tasks used. These variables are: The presentation rate of the auditory information, the demand to switch orientation between the ears, and the competition of the irrelevant channel in the dichotic task. The large saccades and the maintenance of directional fixation observed in Experiment I seem to indicate the combined effect of these variables. The common denominator of the three variables appears to be their effect on the degree of difficulty of the selective listening task. This interpretation is consistent with Kahneman's (1973) discussion of the determinants of mental effort. Some of the relevant variables described in this discussion are: the amount of information per unit time, the number of simultaneously presented stimuli and their discriminability, and the demand changes of selective set. The same variables controlled the size and frequency of Ems in the present experiments.

The amount of effort demanded by the listening task appears, therefore, to have a determining role in the elicitation of the directional Ems response. It should be noted, however, that this effort must involve some difficulty in keeping track of the relevant information channel, since the mere presentation of auditory messages to one ear at the fast rate of $2 / \mathrm{sec}$ (Experiment II) did not affect the directional Ems response, even though messages were located in a certain ear-i.e., a definite spatial location. The spatial location of the relevant information becomes critical only when the proper adaptation and maintenance of a selective set becomes a problem. Then the eyes move and fixate in the direction of the relevant channel. 
A review of the studies dealing with Ems in visual processing tasks reveals that, in addition to its obvious function in visual selection, the Ems mechanism appears to play an-important role in the formation and maintenance of a selective set. The most relevant demonstration for the present discussion of the correspondence between selection and Ems has been made in two studies (Bryden, 1961; Crovitz \& Daves, 1962), which showed significant correlation between the part of the visial field most accurately reported in the brief tachistoscopic exposures and the first postexposure Ems. These postexposure Ems, of course, could have no direct effects on sensory registration, since they occurred after the presentation of the relevant material. Similarly, systematic Ems occurred in the present experiments, although they could not affect directly the perception of the relevant auditory material. The role of the Ems mechanism in both cases appears to be the same; that is, Ss appear to use Ems to emphasize the desired direction of attention.

The results of the present experiments suggest that the Ems mechanism is most likely to be involved when the maintenance of a selective set is difficult and when rapid orientations and reorientations are demanded. The Ems response, therefore, can be considered as part of a general orientation pattern, although its usual function is in the field of visual perception. Some Ss, who were aware of their Ems during the listening task, reported that they occasionally tried to resist the movement in a certain direction or moved the eyes in the opposite direction. They claimed that selective listening became much more difficult when the orientation pattern was not compatible with the direction of the relevant message.

Finally, we turn to the apparent contradiction between the close relation of Ems to the general demands of the listening task and the lack of relation between Ems and specific errors of listening. This contradiction may be solved on the assumption that the selective listening process consists of two distinct stages: The first stage involves the formation of a preliminary selective set, while the second involves more specific operations. Ems in selective listening correspond to the first stage, but not to the second.

Such a hierarchical description of the selective process is in line with several theoretical approaches like the "preattentive phase" of Neisser (1967) and the "filter theory" (e.g., Treisman, 1969). It seems reasonable to further assume that the formation of such preliminary set is facilitated when the relevant source of information has a definite spatial location. Kahneman (1970) has discussed the special significance of spatial location as a designator of information channels.

\section{REFERENCES}

Broadbent, D. E. Perception and communication. London: Pergamon Press, 1958.

Bryden, M. P. The role of post exposural eye movements in tachistoscopic perception. Canadian Journal of Psychology, $1961,15,220-225$.

Crovitz, H. F., \& Daves, W. Tendencies to eye movement and perceptual accuracy. Journal of Experimental Psychology, $1962,63,495-498$.

Gaarder, K. Fine eye movements during inattention. Nature, $1966,209,83-84$.

Gopher, D., \& Kahneman, D. Individual differences in attention and the prediction of flight criteria. Perceptual \& Motor Skills, $1971,33,1335-1342$.

Kahneman, D. Attention and effort. Englewood Cliffs: Prentice-Hall, 1973, in press.

Kahneman, D. Remarks on attention control. In A. F. Sanders (Ed.), Attention and performance III. Acta Psychologica, 1970, 33, 118-131.

Mackworth, N. H., \& Bruner, J. S. Selective visual information during recognition by adults and children. Monograph of Harvard University Center for Cognitive Studies, 1966.

Neisser, U. Cognitive psychology. New York: Appleton-Century-Crofts, 1967.

Obrist, P. A., Wood, D. M., \& Perez-Reyes, M. Heart rate during conditioning in humans: Effect of UCS intensity, vagal blockade and adrenergic block of vasomotor activity. Journal of Experimental Psychology, 1965, 70, 32-42.

Obrist, P., Webb, R., Sutterer, Y., \& Howard, Y. Cardiac deceleration and reaction time: An evaluation of two hypotheses. Psychophysiology, 1970, 6, 695-707.

Obrist, P. A., Webb, R., \& Sutterer, J. R. Heart rate and somatic changes during aversive conditioning and simple reaction time task. Psychophysiology, 1969, 5, 696-723.

Schackel, B. Eye movement recording by electro-oculography. In W. D. Venables and I. Martin (Eds.), A manual for psychophysiological methods. Amsterdam: North-Holland, 1967.

Treisman, A. M. Strategies and models of selective attention. Psychological Review, 1969, 76, 282-299.

Webb, R. A., \& Obrist, P. A. Physiological concomitants of reaction time performance as a function of preparatory interval, and preparatory interval series. Psychophysiology, $1970,6,389-404$.

Yarbus, A. L. Eye movement and vision. New York: Plenum Press, 1967.

\section{NOTE}

1. At the rate of $1 / 0.75 \mathrm{sec}$, the alternation intervals were: $2.25,3.75$, and $6 \mathrm{sec}$ in order to avoid the segmentation of digits.

(Received for publication November 17, 1972; revision received March 28, 1973; accepted A pril 13, 1973.) 